\title{
Utilizing Experiments Designed Results during Error Identification and Improvement of Business Processes
}

\author{
Zuzana Hajdu $^{(1)}$, Marek Andrejkovič ${ }^{(2)}$, Ladislav Mura ${ }^{(3)}$ \\ ${ }^{(1),(2)}$ Faculty of Business Economics of the University of Economics in Bratislava \\ with seat in Košice, Department of Mathematics and Informatics, Tajovského 13, \\ 04130 Košice, Slovakia; e-mail: zuzana.hajduova@euke.sk \\ (3) \\ Faculty of Social Sciences, University of Ss. Cyril and Methodius in Trnava, \\ Nám. J. Herdu 2, 91701 Trnava, Slovakia; e-mail: ladislav.mura@ucm.sk
}

\begin{abstract}
The improvement of business processes is a necessary part of innovations in business, aimed at improving of customer satisfaction and achieving more reliable productions. The above mentione of steps are inevitable in today's world of high competitiveness and therefore the need for improvement of competitive abilities of an enterprise and its products grows steadily. Excessive error rate creates additional costs that are reflected in the price of the product. This is the reason for less effective competitive ability of the given product. Therefore, this contribution shows designed experiments as a method of decreasing error rate in production processes.
\end{abstract}

Keywords: Quality; business processes; DOE; process improvementt

\section{Introduction}

Design of experiments represents a very important step towards the improvement of processes and towards the optimization of production. Optimization in this sense must be understood as a whole, not only as a minimization of errors. In this case, minimum of errors may also be achieved by not producing at all, which, of course, is not the aim of any enterprise. For this reason, this contribution points out the optimization of selected business processes with the aim of improvement of quality within the given enterprise in the sense of improvement of production processes. The statistical software SAS version 9.2 and SAS Enterprise Guide 4.2 will be used for supporting statistical calculations. The aim of this contribution is to improve the existing processes in the selected enterprise by means of optimization methods. With this aim, various methods wil be used, such as observation, analysis, synthesis, methods of inductive statistics, optimization methods, mathematical modelling and many more. 


\section{Design of Experiments}

Design of experiments (DOE) is in literary works also called statistically designed experiments (statistically designed experiments). (El-Haik - Yang, 2003)

Experiment is a process that is prepared and organized in order to better understand the measured subject. Experiment consists of a set of trials which are diferentiated from each other by individual settings of factor levels. A factor is any definite cause that may influence the response. Factors are further divided according to various points of view. The experiment and the subsequent analysis of data obtained aims at finding the causal-consequential relationships between inputs and experimented factors in the process. (Anderson - Lorenzen, 1993)

Researches of many authors have come to a conclusion that DOE is currently not utilized enough (Gremyr et al., 2003 and Bergquist and Albing, 2006). Tanco et al. (2007) has found out that as many as 94\% branches of industry use experiments, however, only in connection with the OFAT (one factor at a time) method.

While carrying out experiments our aim is to establish a mathematical functional relation:

$$
y=f\left(x_{1}, x_{2}, \ldots, x_{n}\right)+\varepsilon
$$

where $\varepsilon$ is the error of the experiment (experiment deviation), $y$ means the response and the $x_{1}, x_{2}, \ldots, x_{n}$ mean factors which should be influenced. This experiment deviation expresses the difference between expected and real values of the response, which means that there is probably no deterministic functional relationship between $y$ and $\left(x_{1}, x_{2}, \ldots, x_{n}\right)$. This can be caused by: (Bailey, 2008)

1. Uncontrollable factors $\left(z_{1}, z_{2}, \ldots, z_{p}\right)$ influencing the response of $y$ which are not contained in the equation (1).

2. The fact that both experiment deviations and measurement deviations are mutually related in a functional relationship $\left(y\right.$ and $\left.x_{1}, x_{2}, \ldots, x_{n}\right)$.

Design of experiments represents a reliable tool. We use it for the observation and study of factors and/or parameters influencing the process in question. Such conduct enables to divide factors into significant and less significant with regard to the conditions of the environment. It also helps to gain information on mutual influence of individual factors $\left(x_{1}, \ldots, x_{n}\right)$. (Anderson - Whitcomb, 2007)

The aim of DOE is: (Phadke, 1989)

- Submit the necessary information with minimum effort and minimum costs,

- Specify whether it is possible to answer the questions by means of the experiment or not, 
- Specify whether a series of experiments or rather a single experiment is desirous,

- Clearly define individual stages of the experiment,

- Utilize previous knowledge and experience to state hypotheses especially when specifying input factors and their levels.

The theory mentions theoretical models, such as "hard" models. These are usually based upon the specified relations stated by theory. They must be based upon the idea of natural sciences and their principles. On the other hand, there are also empirical models, the so called "soft" models. In these we describe relationships between factors and their response on a local interval. (Montgomery, 2005)

The aim of this stage of DOE is, above all, to identify all relevant factors that will further appear in the analysis and also to describe their mutual interaction. The identification of these factors may be performed by means of brainstorming, especially by directed brainstorming. There is also the need to specify the levels of individual factors which will be later used in the experiments. In general, two levels of each factor are sufficient - a minimum and a maximum one. (Pyzdek Keller, 2009)

Design of an experiment must also include any and all restrictions (drawbacks) that may occur during the course of individual stages of the experiment: (Phadke, 1989)

- economic restrictions - if we observe a great number of factors

- time restrictions - if there must be multiple experiments due to a great number of factors

- process restrictions - following from the fundamental principle of the process, where it is impossible to set individual levels of factors

- factor restrictions - in case no level can be specified at all

- diversity of results - if we get different result while having the same setting of factor levels - due to this, individual stages of the experiment must be repeated

The importance of designing experiments lies also in the fact that only necessary experiments are performed. Also, there is a need to state the aim of such experiments. Such formulation clearly shows how to achieve improvement.

\section{Methodology of Research}

Improvement of quality and processes in businesses is the fact that helps businesses become more competitive. The customer pressure to have get better quality as well as internal pressure to decrease the number of defect products and 
the effort to produce less waste creates predispositions for the implementation of mathematical and statistical methods, the aim of which is to optimize the above production processes. Such methods may result in lower enterpreneurial costs either directly, in the form of lower production costs, or indirectly, by lower costs for repairs and/or customer claims. This method may also be used to increase profits.

This contribution shows how to improve existing processes in a selected enterprise by means of optimization methods. This main aim is fulfilled through statistical and mathematical methods as well as through managerial methods.

The process of production has been identified in the enterprise. We analyzed the production process by means of observation and analysis of individual stages and sub-processes. We created process maps. The identification of these subprocesses was vital in order to identify further possibilities of quality improvement. Wrong understanding of production processes may cause the failure of optimization. After the analysis of processes we identified critical points, in our case we measured the number of faults and analysed their occurence in processes. By means of a Pareto diagram we identified the most common failures and concenrated our attention upon them.

During the effort to improve a selected failure we used the Ishikawa diagram in which we identified possible causes of this fault that may have happened in the given production process. We need to emphasize that we fully cooperated with the employees of the enterprise who provided many opinions and tips as to the possible origination of this key fault. Subsequently, after the identification of causes we analysed the production process again, this time with a special emphasis on the observed defect.

During this minute observation of the production process we discovered two key factors that may have influence the origination of the above faults. These factors were subsequently used to design an experiment further conducted in this enterprise. This designed experiment was conducted in the form of a $2^{\mathrm{k}}$ full factor experiment. I.e., each factor was observed on two levels. These levels were specified according to recommendations of the Chief Production Manager and our observation of production processes.

After having conducted the experiment and measuring the response, we started to analyse results and tried to find the optimal setting of the factors in order to minimize the number of defects. Apart from this, we also focused our attention to finding other possible improvements that could optimize the overall production process in the given business company while taking into account real procurement costs of such investments.

During this solution we used methods such as observation, analysis, synthesis, deduction and induction, and also mathematical and statistical optimization methods, method of designed experiments, regress and correlation analysis and testing of statistical hypotheses. 
The improvement of processes has taken part in an enterprise in Hungary in a relative vicinity of Budapest. In the year 2012 we were addressed by the representatives of this enterprise and asked for help with the improvement of their production processes.

\section{Production Process and Experiments}

This part will show the results we analysed and measured in the company. Also analyses that we performed.

\subsection{Description of Production Process}

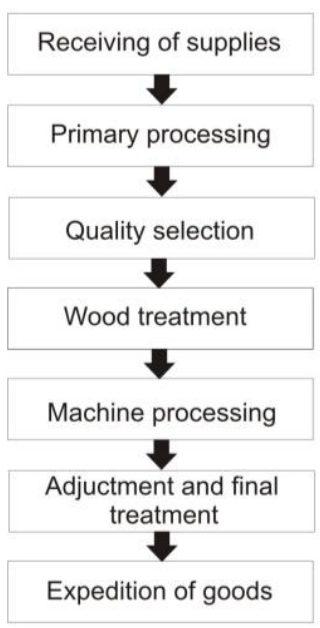

Figure 1

Production process

Production process of wood parquet consists of several stages that will be described in this part. The production process consists of seven main production stages, each of these has also its internal stages. We will describe them one by one.

The first stage starts by receiving supplies to the factory dealing with the production of wood parquet. This stage consists of the delivery and unloading of wood material from trucks.

Second stage consists of processing and cutting of raw wood and its preparation for further processing within the production process. 
Stage three represents the selection of suitable wood material that has been cut for further processing according to its quality. Three groups are formed in this stage, namely, first quality, second quality and waste wood that fails to meet the quality requirements.

Subsequently stage four consists of the treatment of wood. In this stage the wood is dried and further treated which is followed by the machine processing consisting of final cutting to required width and length and planing.

After machine processing, there is again the selection of quality products. Afterwards, groove and tongue are cut in the wood parquet and the surface is ground. After such processing and subsequent quality control there are final treatments that shall provide for the removal of possible faults.

In the end, the wood parquet is packed and placed onto euro-pallets in larger bulks containing appr. $130 \mathrm{~m}^{2}$ and weighing appr. 800-1100 kilograms. Then these pallets are placed into the store and further dispatched upon individual orders.

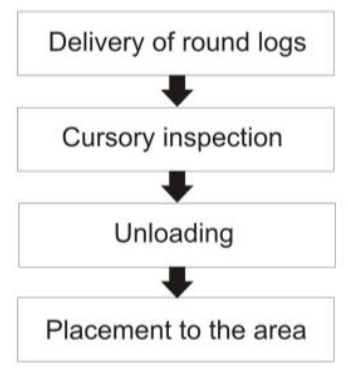

Figure 2

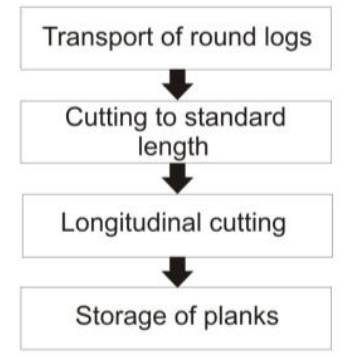

Figure 3

First sub-process - Receiving of supplies

Second sub-process - Primary processing

The first stage consists of the delivery of round logs. These are usually delivered by trucks. However, there is a railroad next to the factory, although not leading directly to the factory. The logs may be delivered also by means of rail transport. Round $\log$ s are delivered from various areas, mostly from Slovakia. After the delivery, the logs are visually checked by the employee in charge. He confirms the receipt of the goods and subsequently orders to unload the trucks.

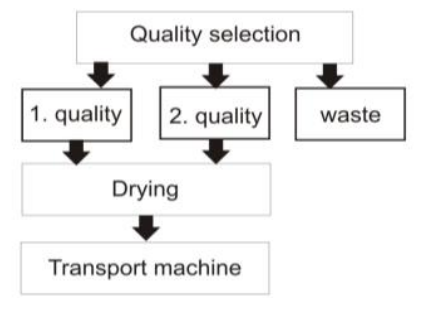

Figure 4

Third sub-process - Quality selection 
After having received the round logs in their storage space on the premises of the factory, these logs are further processed and cut to standard length of 4 meters. Such 4-meter round logs are further transported to longitudinal cutting during which the logs are cut into wood planks 4 meters long. The thickness of such planks is appr. $20 \mathrm{~mm}$. Afterwards, the planks are stored in the stock.

After having cut the wood into planks, these are subdivided according to their quality into two qualitative levels, namely:

- 1. Quality class,

- 2. Quality class,

- waste.

This sorting is performed according to the bark on these planks. In case the bark is damaged, this may create predisposition for bad internal conditions of the wood, e.g. the existence of bark beetle or other worms, and/or dry-rot inside wooden planks.

Subsequently, the wood is dried to achieve the humidity of $8-12 \%$. Such drying takes approximately 48 hours, i.e. 2 days. After two days, wood planks are further transported for processing by means of carts pushed by the employees.

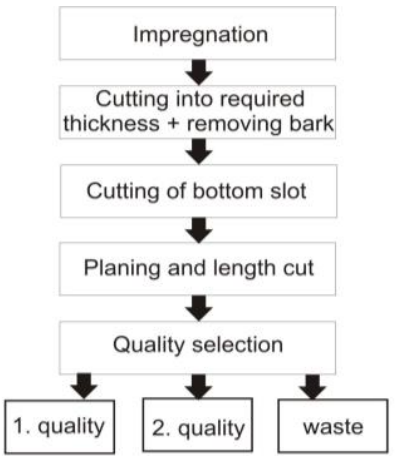

Figure 5

Fourth sub-process - Wood treatment

In this stage, only products that have been marked as either first or second quality follow to another stages. The dried wood is impregnated against possible future woodworm exposure. After impregnation, the planks are cut into required width and the bark is removed from the edges of the planks. After this step, the bottom slot may be cut out. In the end, the wood is planed so that the surface is relatively smooth without coarse structures. After this treatment the planks are cut into final length. Subsequently, they are again assessed as to the quality and they are subdivided into three groups as listed in the previous stage. 
After the adjustment of planks into their final length and width in the previous stage, the planks undergo final treatment consisting of manual sealing. Then, a machine cuts out the groove and tongue at the edges of the parquet. After a succesful cutting, the surface is machine ground so that ists surface is smooth. After this treatment, the products are assessed according to their qaulity. First quality products are faultless. Second quality represents products with slight faults that may be repaired. Recognized faults are manually sealed and subsequently, the plank surface is machine ground again.

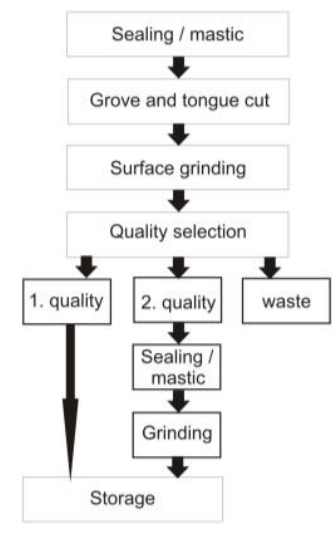

Figure 6

Fifth sub-process - Machine processing

After final treatment, the parquet is transported into the stock. Here they are packed into boxes, in one box there are five layers of parquet placed on top of each other. The pallet is wrapped and tied so that the parquet is not harmed during transport. After having tied and wrapped the pallet, this is transported to the stock of final products and prepared for dispatching for a customer. This factory only delivers parquet in large bulks and works upon individual orders. Therefore, it is not necessary to prepare small consumer packages and the storage through palletts is suitable and sufficient for the needs of the customers.

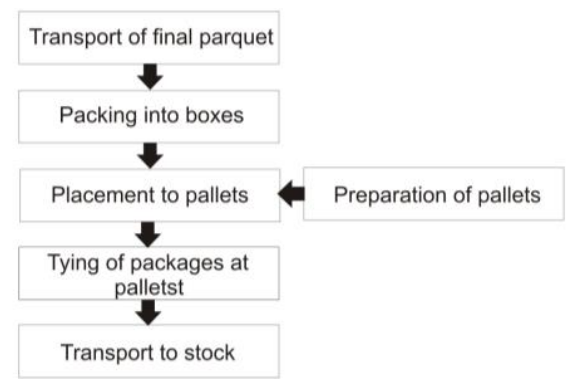

Figure 7

Sixth sub-process - Adjuctment and final treatment 
During the production process, waste material occurs. Tihis waste is not a standard communal waste, but these are products of insufficient quality. Such faulty products are spearated in the production process.

Technically, the origination of faulty products is as follows:

1. primary processing, in which they refuse unsuitable pieces of wooden logs and cut thick planks that are unsuitable for further processing,

2. after machine processing, where some faults can be discovered after planning and cutting of the wood into required length and thickness due to the following reasons:
a. nodes,
b. colour,
c. dry rot,
d. wrong length,
e. other,

3. last stage, in which faulty products may occur is before packaging, when the parquet may be damaged during the cutting out of groove/tongue or during grinding. Several of these faults are impossible to be repaired.

The assessment of ratio of depreciation and the fact whether the product may be repaired into a suitable shape or no is done by a technician who assesses every item indivually. This may cause delay in many cases. Any and all products and parts marked as unsuitable are held on a separate place. Waste consists also of sawdust and wood material that was left after having processed the parquet, namely cuttings. These are processed in the following way.

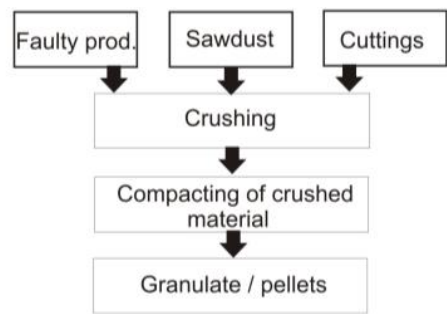

Figure 8

Waste processing in company

Subsequently, these wood remains are processed into crushed material that is compacted by means of a high-pressure compact press. The result is in the form of granulate or pellets. 


\subsection{Analysis of Errors in the Process}

During production process we identified the origination of faults. With regard to the long-term production plan in this enterprise, we identified an individual set of errors. In the communication with the factory workers we found out that our assesment of errors and measured number of faults is really close to a real longterm condition in the enterprise.

We found out that the following errors are most likely to occur:

- Black longitudinal lines,

- Black vertical lines,

- Inaccurately cut grooves,

- Jagged edges,

- Faults in wood material.

Most frequently, the fault of longitudinal black marks occurs during production. In most of the cases, these marks cause the product to be marked as faulty because it is impossible to remove them from the surface. Therefore, we decided to find reasons for these black marks and created an Ishikawa diagram showing these reasons.

During research of individual possibilities the most probable cause of such marks was identified as black supporting wheels that prevent the parquet from elevation during machine processing. The parquet moves on a conveyor belt between individual machines during the processing. Due to this reason, we decided to further study only these objects and tried to remove this fault, or, at least, minimize its occurence.

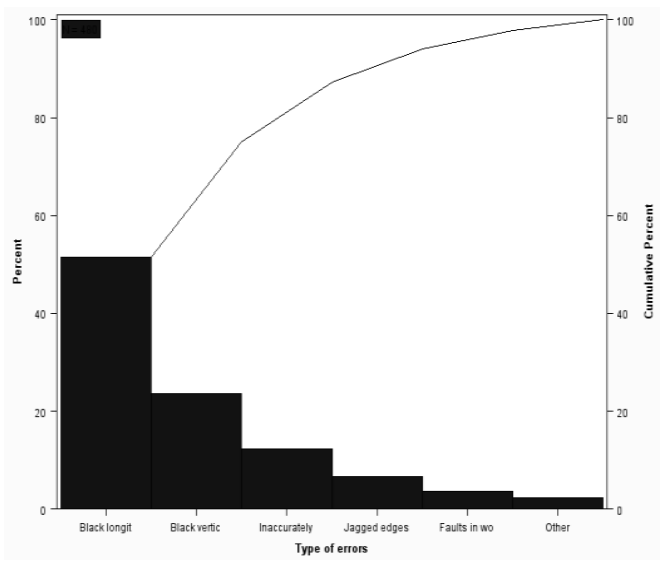

Figure 9

Pareto diagram of errors in company 


\subsection{Design of Experiment}

With this purpose, we concentrated or attention to the problem of supporting wheels the surface of which is made of rubber. During the assessment production we found out that these wheels get stuck sometimes and subsequently the surface of the produced parquet is damaged.

With regard to the above, we decided to explore the influence of two variables:

- Velocity of conveyor belt and, therefore, of parquet,

- Pressure of wheels to the conveyor belt, therefore, to the parquet itself.

That is why we defined an experiment in which we shall take into account the above parameters. We decided to perform a full factor experiment. We set two levels of each factor as follows:

Chart 1

Levels of factors used in experiment

\begin{tabular}{|c|c|c|}
\hline Factor & Minimum level & Maximum level \\
\hline Pressure & 100 & 200 \\
\hline Speed (Velocity of movement) & 50 & 150 \\
\hline
\end{tabular}

Subsequently, we performed measurements for all combinations, whereas we decided to perform four replications of the given experiment. This means that we measured individual settings one by one, each of the settings was measured four times.

Input values can be seen in the following figure from software SAS 9.2 that was used for planning and calcualtion of individual values of the experiment.

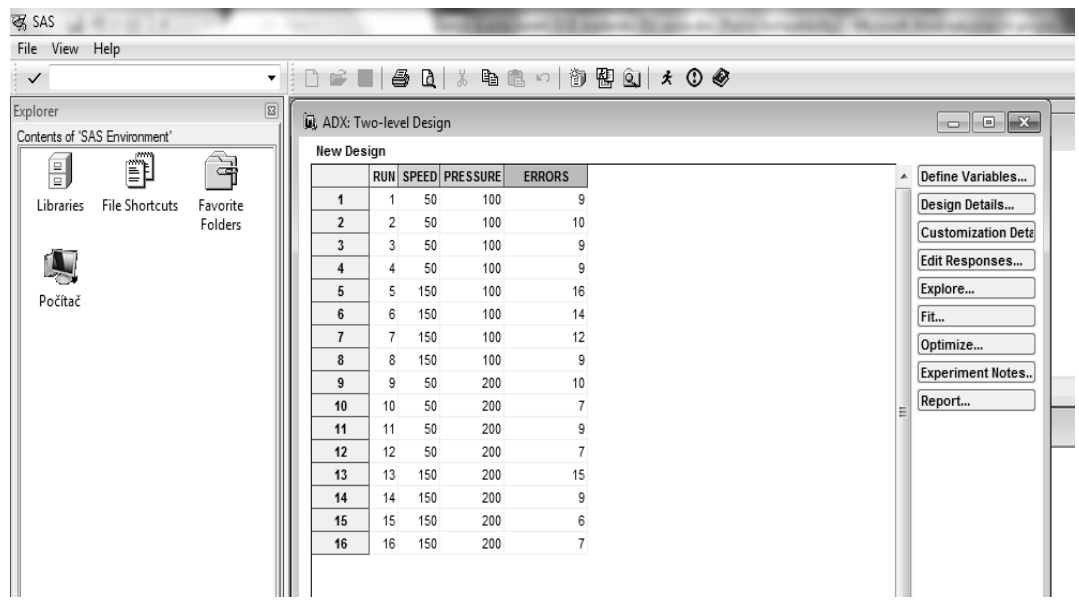

Figure 10

Input measurements of Factors and Response 


\section{Results and Discussions}

\subsection{Discussion}

Now we may show the output that points out the number of errors we measured. The graph describes the number of faults discovered on produced parquet in the same part of the production batch. We always changed the settings after having produced the same production batch which was, in our case, 200 pieces of parquet produced continually.

It is clear that the largest number of errors was detected in Batch 5 where we obtained as many as 16 faulty pieces of parquet.

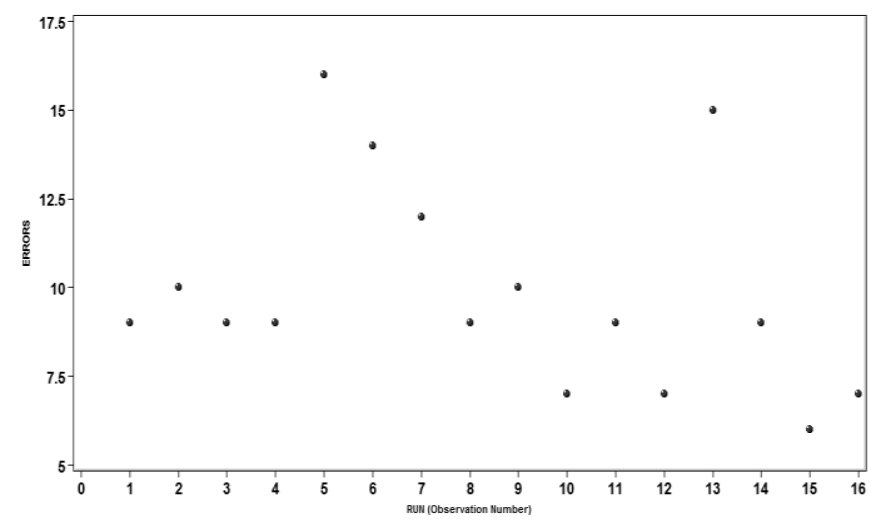

Figure 11

Chronological measurements of Result (Errors)

Upon these measurements we calculated the influence of individual factors. We can see that the higher velocity of movement results in higher occurence of faults. On the other hand, the analysis of pressure showed opposite results. The higher pressure was applied to the cylinder (wheel), the lower number of faults occured.

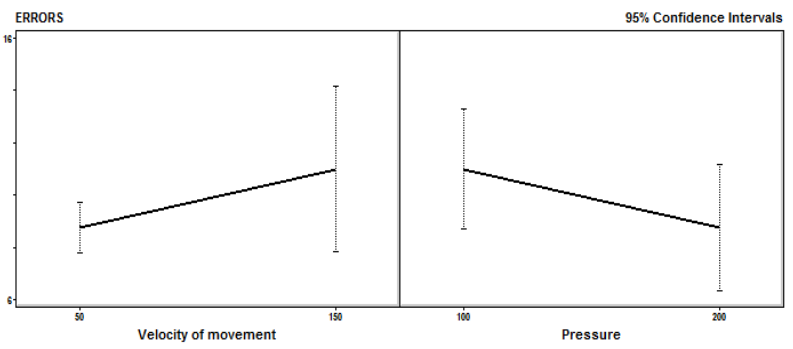

Figure 12

Graph of influence of Level of factor on Response 
Apart from this, we also decided to explore mutual interactions between these two variables. We found out that the interaction between these variables is not significant because the curves do not intersect, what would have been a sign of important interaction. From this reason it is not necessary to explore the development of interaction because it means that the influence of both factors at the same time is not significantly higher than the sum of their influences analysed individually.

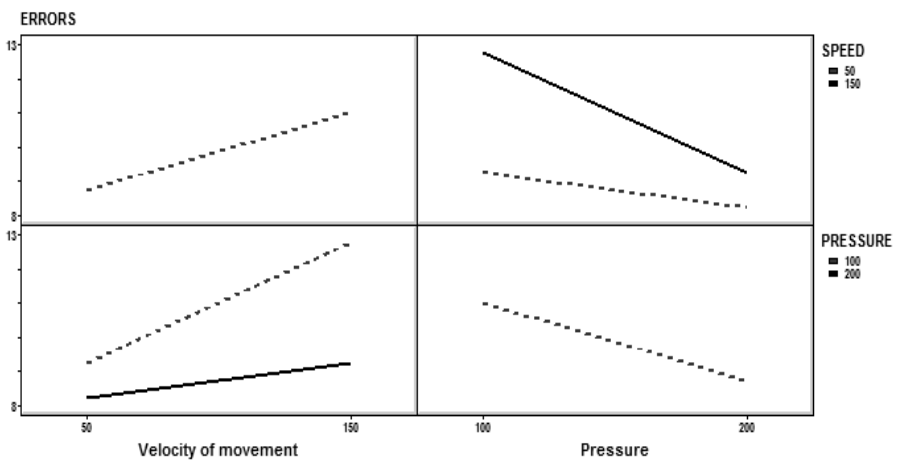

Figure 13

Interaction of factors measured on Response

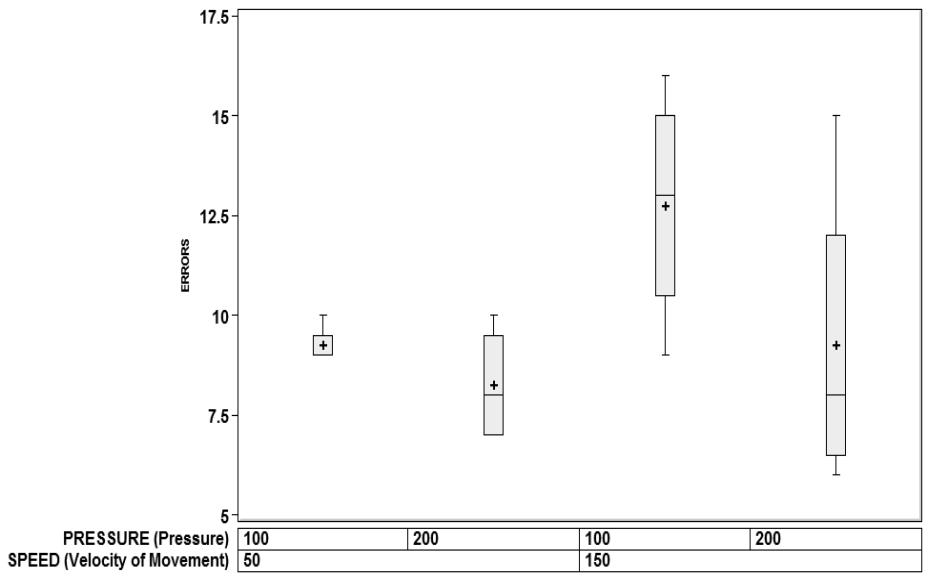

Figure 14

Divisions of individual subfiles based on levels of factors

Subsequently, all researched groups were shown in box plots that represent results of measurements. However, we need to emphasize that these box plots consist of only four data and therefore cannot be understood in an exact way. What occurs as a very important phenomenon is the fact that in case of low speed the number of faults is smaller than in case of higher speed. 


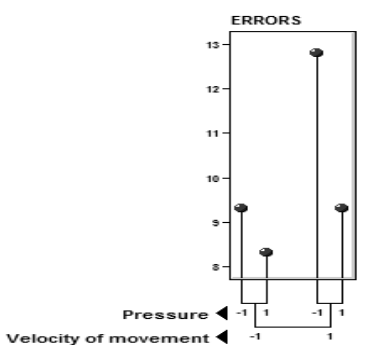

Figure 15

Group averages

The above fact may be described by means of a point graph that shows average values of individual groups.

Apart from this, we also calculated $95 \%$ Prediction intervals for the curves of influence of individual factors to the number of faults.

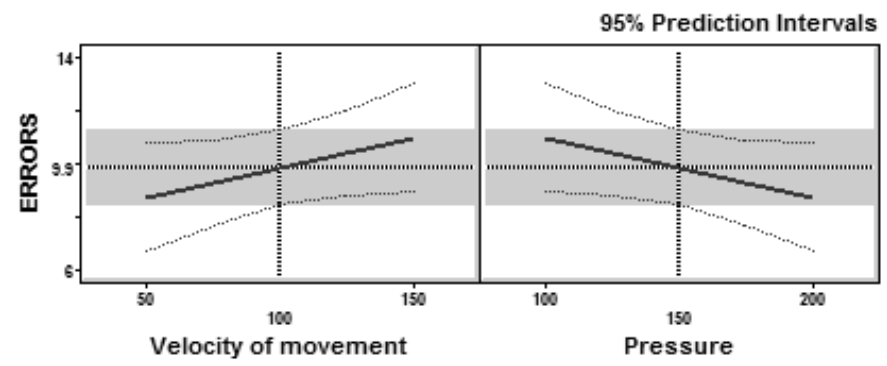

Figure 16

Reliability intervals of individual groups

Upon the above measurement we further defined a predictive model that serves the purpose of calculating the expected number of faults at a given speed and presuure.

\begin{tabular}{|l|l|l|}
\hline \multicolumn{2}{|l|}{ Predictive Model for FAULTS } & \\
\hline \multicolumn{2}{|l|}{$\begin{array}{l}\text { 9.875 + 1.125*SPEED - 1.125*PRESSURE - } \\
0.625 * \text { SPEED*PRESSURE }\end{array}$} & \\
\hline ERRORS & \multicolumn{1}{|l|}{} \\
\hline & & \\
\hline & $\begin{array}{l}7.25+0.06 * \text { SPEED + 0.0025*PRESSURE - } \\
0.00025 * \text { SPEED*PRESSURE }\end{array}$ & \\
\hline ERRORS & $=$ & \\
\hline
\end{tabular}

Figure 17

Predictive model for the number of faults 
The above conclusions may be represented by means of a so-called „contour graph" that shows the number of faults through increase of surface in a twodimensional area with the help of the so-called „contour lines“. This graph shows that the smallest number of faults occurs at a higher pressure and slower speed of movement.

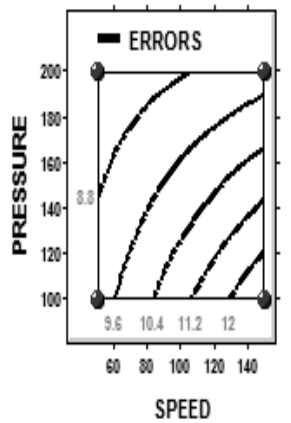

Figure 18

Contour plot for the number of faults

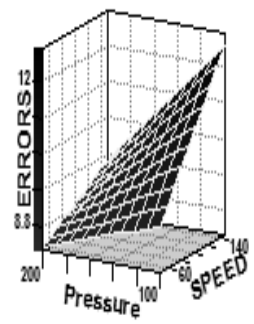

Figure 19

3D surface graph of Response

The above conclusion may also be shown by means of a 3D graph in which we can see that the lowest number of expected faults is likely to be expected at higher pressure and lower speed of the conveyor, i.e. parquet on the production line.

Upon these analyses and results we may subsequently define recommendations that form the content of the next chapter.

\subsection{Recommendations}

Upon the above analyses we can define the following recommendations for the enterprise. We found out that the most optimum setting of the given factors is as follows:

\begin{tabular}{|c|c|c|c|c|}
\hline \multicolumn{5}{|c|}{ Prediction Profile Settings } \\
\hline SPEED & & 50 & & \\
\hline & $\begin{array}{l}\text { of } \\
\text { movement }\end{array}$ & & ERRORS & $\begin{array}{r}8.25 \\
{[6.817455,9.682545]}\end{array}$ \\
\hline PRESSURE & Pressure & 200 & Desirability & $48.44 \%$ \\
\hline
\end{tabular}

Figure 20

Optimum factor setting

The factory should therefore set the speed of the conveyor, and, thus the movement of the parquet to level 500 and at the same time, increase the pressure of the cylinder to the level of 200 Newton, which is appr. $20 \mathrm{~kg} /$ force to a given 
parquet. As the load-bearing capacity of individual parquet is much higher, these are safe from harm.

Apart from this, there is the need to regularly perform lubrication of bearings of these wheels and cylinders that help to press the parquets to the conveyor during their movement on a production line. It is important to ensure that the excessive oil or vaseline does not spray from these bearings during the movement of wheels or cylinders. For this reason, there is a need to use suitable lubrication oils that are solid enough but have sufficient characteristics. Another problem that requires constant attention is the correct shape of wheels and cylinders. In case they are repeatedly stuck, they are often misshapen and such small damages may cause the wheel and/or cylinder to get stuck again and the damage may become greater. For this reason, there is a need to regularly replace these wheels and cylinders and check them in order to prevent such stucking and damaging of the material.

Apart from this, there are some other improvements that may be implemented in this enterprise and that we encountered during our work in the factory through solving the previous task.

We found out that the factory uses a lot of pushcarts for the manipulation with the material. It would be useful to think of their replacement by conveyor belts as these would transport the parquet more carefully, because many times there was the damage to the material due to bad handling and/or inattentiveness. The transfer takes place between three production halls which are interconnected by means of roofed corridors. These corridors may be used for the construction of conveyor belts that would automatically transfer the semiproducts between individual construction stages.

Apart from this, another problem is the failure to perform the steeping of the wooden parquet. These wooden parquet are used in the interior. Steeping currently takes place only at the application in the interior and three layers of steeping must be performed. Each new layer may be applied only after complete drying of the previous one. Therefore, the primary steeping at the factory would save a lot of time. Moreover, such steeping may be performed automatically and as such saves costs also in the form of a labour force.

\section{Conclusions}

We applied designed experiments in a concrete enterprise that deals with the production of wood parquet. By means of this method we achieved the improvement of production through less errors, i.e. less faulty products causing additional costs for the factory. The use of planned experiments is very effective in company activities. Such experiments represent the way of improving business processes at relatively low costs, and describe the method of effectively spent improvement costs with the aim of achieving aimed improvement of business proccesses. Upon the above we came to conclusions described in the last paragraph of this contribution. Listed improvements helped the factory to gain 
a better place on the market due to lower costs caused by faulty products and subsequent possibility to offer lower sale price to the customers. In such way, we achieved a higher competitiveness of products of this company.

\section{Acknowledgement}

This paper was supported by the research project VEGA No. 1/0822/13 „Energy efficiency and economic support of regional energy policies".

\section{References}

[1] Anderson, M. J. - Whitcomb, P. J. 2007. DOE Simplified: Practical Tools for Effective Experimentation. New York : Productivity Press, 2007. ISBN 978-1563273445

[2] Anderson, V. - Lorenzen, T. 1993. Design of Experiments. New Jersey : CRC Press, 1993. ISBN 978-0824790776

[3] Bailey, R. A. 2008. Design of Comparative Experiments. Cambridge : Cambridge University Press, 2008. ISBN 978-0521865067

[4] BERGQUIST, B. - ALBING, M. 2006. Statistical methods-Does anyone really use them? In: Total Quality Management \& Business Excellence, 17(8):961-972

[5] Box, G. E. P. - Hunter, J. S. W. - Hunter, G. 2005. Statistics for Experimenters-Design, Innovation and Discovery. $2^{\text {nd }}$ ed. New Jersey: John Wiley \& Sons

[6] El-Haik, B. - Yang., K. 2003. Design for Six Sigma: A Roadmap For Product Development. New York : McGraw - Hill, 2003. ISBN 0071412085

[7] Gremyr, I. - Arvidsson, M. - Johansson, P. 2003. Robust design methodology: A status in the Swedish manufacturing industry. In: Quality and Reliability Engineering International. 19:285-293

[8] JMP. 2005. Design of Experiments. Cary : SAS Institute, 2005. ISBN 159047-816-9

[9] Lewis, J. P. 2007. Fundamentals of Project Management. 3rd ed. AMACOM, United States

[10] Lye, L. M. 2005. Tools and toys for teaching design of experiments methodology. In: 33rd Annual General Conference of the Canadian Society for Civil Engineering, 2-4 June 2005, Toronto, Ontario, Canada

[11] Montgomery, D. C. 2005. Design and Analysis of Experiments. New Jersey: John Wiley \& Sons

[12] Phadke, M. 1989. Quality Engineering Using Robust Design. New Jersey : Prentice Hall, Upper. 1989 
[13] Prokeinová, R. 2009. The impact of ecological footprint in enterprise decision-making. In: Scientia Iuventa 2009: proceedings of reviewed papers from international scientific conference of PhD. Banská Bystrica, 2009

[14] Pyzdek, T. - Keller, P. 2009. The Six Sigma Handbook. New York : McGraw Hill Professional, 2009. ISBN 978-007162338-4

[15] SAS. 2005. Concepts of Experimental Design. Cary : SAS Institute, 2005

[16] Stehlíková, B. Statistical Analysis with SAS System. Nitra: SUA, 2003, $127 \mathrm{p}$.

[17] Tanco, M. et al. 2007. Is Design of Experiments really used? A survey of Basque Industries. In: Journal of Engineering Design. 19(5):447-460

[18] Viles, E. et al. 2009. Planning Experiments, the First Real Task in Reaching a Goal. In: Quality Engineering, 21: pp. 44-51, 2009 ISSN: 0898-2112 